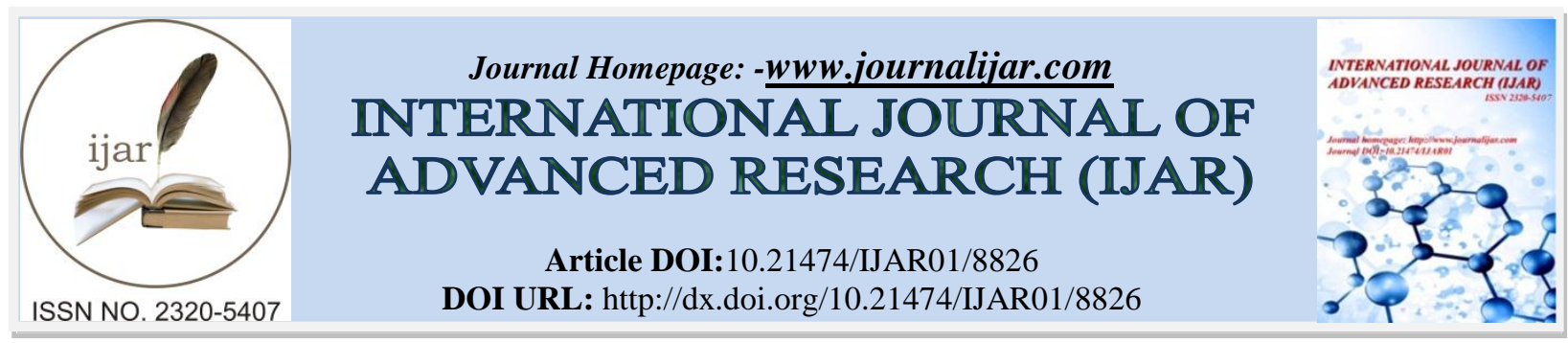

RESEARCH ARTICLE

\title{
SURGICAL TREATMENT OF THE PATENT DUCTUS ARTERIOSUS IN ADULTS: ABOUT FIVE CASES.
}

\section{M.j. Rhissassi, H.Wazaren, H.Bouhdadi, M.M. Maharazou, A.Aghzar, i.benabderrazak, N.El Moktadir, I.Maaroufi , C.Benlafqih, R.Sayah and M.Laaroussi.}

\section{Manuscript Info}

Manuscript History

Received: 06 February 2019

Final Accepted: 08 March 2019

Published: April 2019
Abstract

\section{Introduction:-}

Patent ductus arteriosus accounts for about $10 \%$ of congenital heart disease. Generally, it is benign in children [1]. The surgical ligature was introduced in 1939 by Huss and Gobbard [2]. Eventhough surgery is still treatment of choice; transcatheter techniques have largely supplanted surgery for closure of PDA [3].

In adults, patent ductus arteriosus is rare. Many anatomical or morphological variations may exist, aneurysms, calcifications or complications such as endarteritis or ventricular dysfunction. The presence of these anomalies drives towards a surgical treatment of the PDA [4].

The objective of this study is to review and analyze the outcomes of surgical treatment of the PDA in adults.

\section{Patients and Methods:-}

This is a retrospective study that includes five adult patients operated for ductus arteriosus persistent between February 2015 and June 2016 in the Department of Cardiovascular Surgery A of the Ibn Sina Hospital in Rabat.

The inclusion criteria were age over 15 years. Symptoms were dyspnea, failure to thrive, or signs of heart failure. All patients underwent surgery and the surgical technique was a ligation section of the ductus arteriosus by posterolateral thoracotomy.

All patients underwent clinical and echocardiographic investigations before the cure, peri-operatively and at one month of follow-up.

\section{Results:-}

Between February 2015 and June 2016, five patients were admitted for surgical treatment of persistent arterial duct. The middle age was 19 years. The male sex was predominant with 4 men and one woman. All patients were symptomatic with exertional dyspnea. 3 patients had cyanosis and failure to thrive was observed in 4 patients ( 3 men and 1 woman). A continuous murmur in the left intraventricular area was perceived in three patients.

Transthoracic échocardiography was performed in all patients. It revealed the presence of the persistence of ductus arteriosus in all patients. The diameter varied between $7 \mathrm{~mm}$ and $25 \mathrm{~mm}$. The left-to-right shunt was present with pulmonary hypertension ranging between $55 \mathrm{mmHg}$ and $75 \mathrm{mmHg}$. Right cardiac chambers were unexplained in all patients. There was enlargement of left ventricle in 4 patients. 
A thoracic computed tomography angiography was performed in a patient. It confirmed the presence of the ductus arteriosus (figure 1)

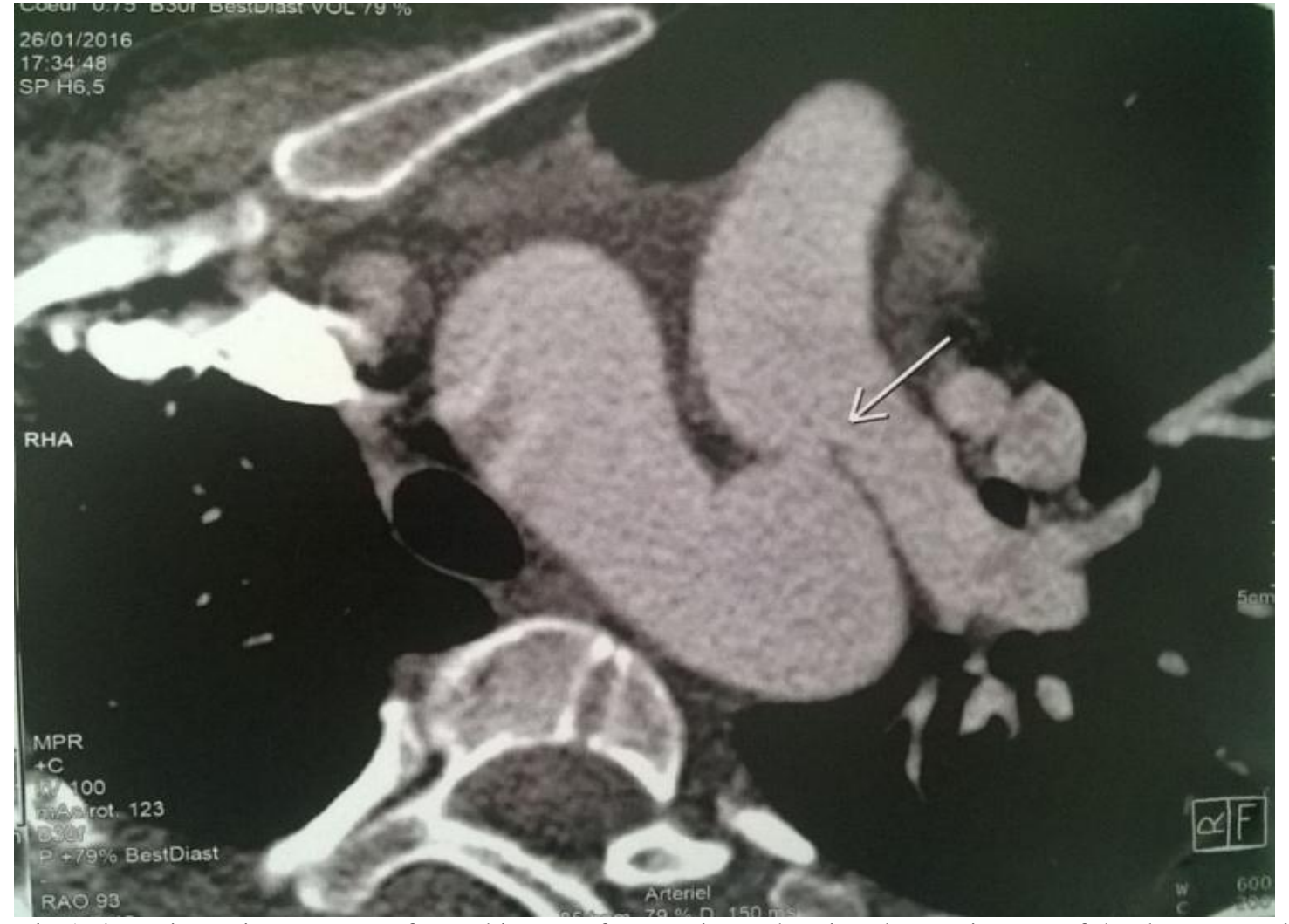

Figure 1:-A thoracic angioscanner performed in one of our patients showing the persistance of the ductus arteriosus.

All patients underwent surgery with ligation section by left posterolateral thoracotomy with cardiopulmonary bypass on standby.

There was no operative mortality, neither, post-operative morbidity.

Patients were reviewed for clinical and echocardiographic control at one month. The same outcomes were noted.

\section{Discussion:-}

The patent ductus arteriosus is a form of congenital heart disease, defined as a persistence of duct beyond the third month of life in infants [1]. It may be associated with other cardiac abnormalities. In adults, it is often isolated [2].

The treatment may be medical, surgical or interventional [3]. Before the emergence of interventional techniques, surgery was the treatment of choice [5]. The technique consists of a section-ligation of the arterial duct through left posterolateral thoracotomy. Thorascopic procedures are probably not appropriate for the adult because of frequency of calcification and the greater the risk of rupture while ligating the ductus [6].

In patients over 40 years of age, or in the presence of severe ductus calcification or aneuvrysm, considiration should be given to performing PDA ligation via a median sternotomy using cardiopulmonary bypass [7].

In children, the outcomes of surgery are associated with lower morbidity and shorter hospital stays [9]. In adults, in presence of a large diameter, an aneurysm, an endarteritis or an abscess of the duct, surgery is indicated. The majority of series reports that the surgery confers a complete closure of the canal in $94-100 \%$ of cases, with a mortalityrate of $0-2 \%$. The endovascular treatment is technically more difficult in adults than in children, so that the surgery is more indicated in adults where it's more safe and effective, confering complete results [9]. 
Surgery may be associated with complications such as bleeding, pneumothorax or injury to the recurrent laryngeal nerve [10]. In our series, no complications were noted.

\section{Conclusion:-}

The PDA in adults is rarer than in children. Surgery is safe and effective with better outcomes than interventional closure.

\section{Refrences:-}

1. Forsey JT, Elmasry OA, Martin RP. Patent arterial duct.Orphanet J Rare Dis 2009; 4:17.

2. Gross RE, Hubbard JP. Surgical Ligation of a Patent Ductus Arteriosus: Report of First Successful Case. JAMA 1939; 112(8):729-31.

3. Baumgartner H, Bonhoeffer P, De Groot NM, et al. ESC Guide-lines for the management of grown-up congenital heart disease (new version 2010). Eur Heart J 2010; 3: 2915-57.

4. Gournay V. The ductus arteriosus: physiology, regulation, andfunctional and congenital anomalies. Arch Cardiovasc Dis2011; 104:578-85.

5. Warnes CA, Williams RG, Bashore TM, et al. ACC/ AHA 2008 guidelines for the management of adults with congenital heart disease. Circulation 2008; 118:e714-833.

6. Mitchell SC, Korones SB, Berendes HW. Congenital heart dis-ease in 56,109 births. Incidence and natural history. Circulation1971; 43:323-32.

7. El bayonsy A, Korfer A, Arusoglu I, et al.Bridging to cardiac transplantation ith the thoracic assist device. Thorac Cardiovsc Surg 1999; 47:307.

8. Sesai A, Shiono M, Orime Y, et al. Major organ function under mechanical support: comparative studies of pulsatile and nonpulsatile circulation. Artif Organs 1999; 23:280.

9. Meadowz J, Landzberg M. advances in transcatheter interventions in adults with congenital heart disease. Progr Cardiovasc Dis. $2011 ; 53(4): 265-273$

10. Toda R, Moriyama Y, Yamashita M, et al. Operation for adult patent patent ductus arterios ususing cardiopulmonary bypass. Ann Thorac Surg 2000; 70(6) :1935-7. 